\title{
A LEI DOS LUGARES VAGOS: O INSÓLITO E A NARRATIVA CRIMINAL PÓS-MODERNA EM FARGO
}

Pedro Sasse (UFF)

Recebido em 27 abr 2020. Pedro Sasse é Doutor em Estudos de Literatura Aprovado em 08 jul 2020. pela Universidade Federal Fluminense na área de Literatura, História e Cultura, e membro dos seguintes grupos de pesquisa (CNPq): "Escritos Suspeitos", "Estudos do Gótico" e "Interferências: literatura e ciência". Possui experiência na área de Teoria Literária e Literatura Comparada, com ênfase em: literatura criminal, literatura distópica, gótico, violência urbana, terror.

Currículo Lattes: http://lattes.cnpq.br/7219234746540444. E-mail: Pedro_sasse@hotmail.com ORCID iD: https://orcid.org/0000-0001-7441-7122

Resumo: Já em 1941, Howard Haycraft, em Murder for Pleasure, obra pioneira na crítica à narrativa criminal, atestava as inúmeras tentativas frustradas de prever o esgotamento do gênero identificado como detective fiction. De lá para cá, não foram poucos os que tentaram decretar a morte do velho romance detetivesco, que sempre encontrou, nas frestas de um modelo engessado, formas novas para se reinventar. Mesmo se nos restringirmos unicamente às noções limitadas do gênero criminal que imperavam à época de Haycraft e, assim, olharmos apenas para a ficção centrada 
em detetives, encontraremos nas narrativas investigativas metafísicas uma vertente em plena sintonia com os motifs da literatura contemporânea, profundamente engajada com uma quebra das convenções do gênero. Proponho, dessa forma, uma ilustração das potências renovadoras do gênero criminal na vertente investigativa metafísica através de um exemplo drástico: a terceira temporada da série Fargo. Drástico porque tal obra reúne diversas condições que a tornariam um perfeito candidato a exemplo de exaustão do gênero: passada em uma cidade do interior em que um crime violento quebra a ordem social - um dos mais antigos enredos do gênero -, a série repete a fórmula do filme e a terceira temporada repete a fórmula das últimas duas. No entanto, através da exploração de temas e ferramentas como intertextualidade, metaficção e subversão de normas do gênero, a terceira temporada da série Fargo - composta, como todas as temporadas, por uma história independente das demais - surpreendentemente apresenta uma narrativa que reflete, questiona e revigora o gênero da narrativa criminal.

Palavras-chave: Ficção de crime; Detetive metafísico; Convenções; Narrativa; Insólito.

Abstract: In 1941, Howard Haycraft, in Murder for Pleasure, a pioneer work of crime narrative criticism, already attested the multiple failed efforts to predict an exhaustion of the genre identified as detective fiction. Since then, quite a few critics have tried to pronounce the death of the old detective novel, which finds, in the cracks of a rigid pattern, new ways to reinvent itself. Even if we remain within the limited notions of crime narrative that prevailed in Haycraft's time and only look up to the detective-centered fiction, we will find in the metaphysical investigative narratives a strand in full alignment with the motifs of contemporary literature, profoundly engaged in a rupture of the genre 
conventions. Therefore, I propose an illustration of the renewing powers of the crime genre in the metaphysical strand through a drastic example: the third season of Fargo series. It is drastic because the work puts together multiple conditions which would make it the perfect candidate to become an example of the genre's exhaustion: taking place in a countryside town where a violent crime breaks the social order - one of the genre's oldest plots -, the series repeats the movie formula and the third season repeats the formula of the previous two. However, through the exploration of themes and tools such as intertextuality, metafiction, and subversion of the genre's conventions, Fargo's third season - an independent story, like the previous seasons - surprisingly presents a narrative that reflects, questions and renews the crime narrative genre.

Keywords: Crime fiction; Metaphysical detective; Conventions; Narrative; Uncanny.

\section{INTRODUÇÃO}

A estrutura básica da narrativa investigativa parece muito propícia ao esgotamento. Diferente de seus irmãos como a fantasia, a ficção científica e o horror, gêneros definidos por temas ou efeitos estéticos - ainda que tenham certos enredos recorrentes -, o principal definidor da dita ficção detetivesca foi, por muito tempo, e em certa medida continua sendo, a base de seu enredo. Em "The Guilty Vicarage", W. H. Auden define a estrutura do gênero em uma fórmula bem simples: "um assassinato ocorre, muitos são suspeitos; todos os suspeitos menos um, que é o assassino, são eliminados; o assassino é preso ou morre ${ }^{1 \prime \prime}$ (AUDEN, 1980, p.15 - tradução nossa).

1 No original: "a murder occurs, many are suspected; all but one suspect, who is the murderer, are eliminated; the murderer is arrested or dies". 
Auden pode ser acusado de ter uma visão muito estreita do gênero, uma vez que uma definição assim acabaria mesmo por excluir parte das histórias do próprio "pai da ficção detetivesca", Poe, com os mistérios de Dupin. Poderíamos abrir um pouco a definição de Auden e dizer: um crime ocorre, um investigador elimina progressivamente hipóteses até chegar a uma solução, a um culpado.

Ainda assim, as possibilidades de variação não parecem suficientes para dar muito fôlego ao gênero. Pode-se variar o crime, mas nem todo crime parece fornecer o mesmo material de interesse para a narrativa, culminando quase sempre em assassinato - corroborando a visão de Auden - e, eventualmente, em roubo. Pode-se variar o investigador, do excêntrico Dupin ou o ainda mais excêntrico Holmes para figuras mais sóbrias como o Padre Brown ou Thorndyke - ou ainda os durões, como Marlowe. 0 desfecho é ainda mais resistente a mudanças. $\mathrm{O}$ criminoso precisa ser encontrado e devidamente punido - permitindo, no máximo, algumas surpresas, como o orangotango da Rua Morgue.

Não estranha, então, que já em 1941, Howard Haycraft, em Murder for Pleasure, um dos primeiros livros inteiramente dedicados a reflexões críticas e teóricas sobre a narrativa investigativa, constatasse as inúmeras previsões frustradas do que seria o declínio do gênero detetivesco. Howard abre seu capítulo "The Future of the Detective Story" com uma epígrafe de um artigo para o London Academy chamado "The passing of the Detective in Literature", datado de 1905 - vale lembrar, período anterior à dita era de ouro da narrativa investigativa. Destaco, em especial, a primeira frase desse trecho: "O detetive literário chega, com muito 
esforço, a quinze anos de idade, mas já começa a cair em declínio ${ }^{2 \prime}$ (HAYCRAFT, 1941, p.319 - tradução nossa).

Haycraft, percebendo com clareza como cada previsão era frustrada por uma nova onda de sucesso do gênero, acompanha a corrente crítica que, em vez de pregar o fim do gênero, vê saídas para evitar o inerentemente potencial esgotamento do gênero, menos através da mudança em sua estrutura base que nas formas de narrá-la:

A fórmula Poe-Gaboriau estava virtualmente extinta quando Conan Doyle veio para ressuscitála e revesti-la em um traje mais colorido. Depois, quando o vestuário romântico fornecido por Doyle começou a se mostrar vergonhosamente curto, o socorro oportuno chegou através de artesãos mestres como R. Austin Freeman, E. C. Bentley, Dorothy Sayers, Francis Iles, S. S. Van Dine, Dashiel Hammett (apenas uma mostra é possível), que produziram em seus muitos estilos, um tipo de história mais naturalista e crível, mais ajustada à vida moderna. Se nós aceitamos essa teoria "cíclica", e nos lembramos também que todas as mudanças anteriores passaram despercebidas até alguns anos depois de seu surgimento, é possível que as sementes de um novo movimento já estejam presentes na ficção detetivesca contemporânea - só que nenhum de nós teve a perspicácia para percebê-las. (HAYCRAFT, 1941, p.323 - tradução nossa)

Haycraft usa a metáfora da roupagem para descrever essa mudança menos na fábula que na narrativa em si, na maneira como essa fábula é organizada e exposta ao leitor. Tal trecho é

2 No original: "The detective in literature is hardly more than fifty years old, but already is passing into decay". 
significativo, ainda, por perceber - sem perceber, desculpem o paradoxo - que as sementes do novo ciclo já estavam presentes entre os escritores mencionados, através de Hammett que, junto a Raymond Chandler, vai se tornar um dos os grandes nomes de uma das mais vigorosas vertentes da narrativa investigativa, o dito romance hard-boiled.

Conforme mudam noções de justiça, popularidade de certos crimes, organização e atuação da polícia, ansiedades sociais, configuração do espaço urbano e predicados artísticos mudam também as roupagens que dão conta de trazer novo fôlego ao gênero. O hard-boiled dá lugar ao police procedural, com crescente foco no narcotráfico de um lado e nos psicopatas de outro. A narrativa investigativa acentua seu vínculo com o ativismo social em narrativas investigativas feministas, negras e queer. $E$, em sintonia com predicados do pós-modernismo, revela suas amarras, questiona suas fronteiras e joga com suas convenções através da narrativa investigativa metafísica, cujas raízes estão em Borges, Georges Perec e Paul Auster.

Nessa última e mais recente vertente, o insólito assume um papel de destaque. Nos dois primeiros grandes ciclos - para manter a sintonia com Haycraft - da narrativa investigativa, o enigma clássico, e mais romântico, e seu sucessor de inclinação realista, o hard-boiled, não há muito espaço para eventos fantásticos. A valorização, ou mesmo a completa centralidade, da razão no enigma clássico pede que qualquer evento aparentemente insólito - todo mistério digno de um romance de enigma começa por ser insólito ou não atrairia a atenção de um detetive tão especial quanto o protagonista de tais obras o é - seja destrinchado 
em fatos claros e coerentes até perder tal aparência. Para as posteriores vertentes de inclinação realista, mesmo quando a razão cede espaço para a paixão - penso aqui no passional detetive do hard-boiled, sobretudo -, essa inclinação ao crível pede narrativas ainda mais sóbrias, em que mesmo os crimes inicialmente insólitos - assassinatos aparentemente impossíveis, mortes exóticas, planos intrincadíssimos para evitar detecção dão lugar aos próprios do espaço realista - assassinatos comuns, corrupção, sequestro, roubo, formação de quadrilha etc.

O tema do sobrenatural em si, manifestação insólita mais explícita possível, poderia ser, e foi por muito tempo, suficiente para excluir uma obra da tradição do gênero criminal, uma vez que deslocaria a preocupação central de uma natureza social - o crime, a investigação e seus desdobramentos legais - para uma natureza ontológica, metafísica - a tensão entre uma concepção prévia de realidade e a brusca expansão dessa concepção diante de um universo cujas leis se diferenciam daquelas encontradas no contexto do leitor.

Se, na história da crítica da narrativa investigativa pouco espaço é dado para obras que exploram temas sobrenaturais, o oposto não é verdade: gêneros mais afins ao sobrenatural não raramente se aproveitam da estrutura básica da narrativa investigativa problema inicial enigmático, investigação, eliminação de hipóteses e solução final. Histórias que partem da fina linha do fantástico todoroviano muitas vezes se afastam de um enquadramento no gênero investigativo apenas na última etapa de seus enredos, em que a solução - que se fosse racional, levaria ao enquadramento no estranho todoroviano e poderia ser reunida a diversas narrativas 
investigativas que jogam com a tensão entre real e sobrenatural, mas sempre advogando em prol da razão ao final, como em "O cão dos Baskervilles" -, ao ser do campo sobrenatural, impede uma associação mais clara com o gênero ${ }^{3}$.

Essa é uma barreira rompida pela narrativa investigativa pósmoderna. Tendo como uma de suas próprias características a ruptura com as convenções tradicionais do gênero, essa vertente explora o insólito nas mais diversas formas, seja mantendo os insólitos crimes já presentes desde o romance de enigma clássico em aberto - e com isso segurando o efeito do fantástico puro todoroviano -, seja expondo as costuras de sua própria ficcionalidade, ou mesmo explorando abertamente a temática sobrenatural como forma de desconstrução do realismo no gênero.

Desejo explorar, aqui, um exemplo em que todos esses usos do insólito se fazem presentes, a terceira temporada da série televisiva Fargo, criada por Noah Hawley, contando com produção executiva dos irmãos Cohen. A obra não é precursora ou expoente da narrativa investigativa metafísica, mas serve como um dos mais ricos exemplos de seu uso nos meios de grande alcance, uma vez que, diferente de ciclos anteriores, o romance detetivesco pósmoderno não atingiu nem em suas raízes nem em seus principais autores, um amplo apelo popular.

3 Lovecraft é um bom exemplo disso em diversos de seus contos, em que a investigação de desaparecimentos ou mortes misteriosas mantém uma estrutura investigativa, mas que culmina em uma causa não do campo do real - logo criminal - mas do campo do sobrenatural, transformando-o um problema de outra ordem. A primeira temporada da série True Detective (2014) percebe muito bem esse potencial e, explorando os mesmos mitos do Rei Amarelo - que surgem em $O$ rei amarelo, de Robert W. Chambers, e reaparecem em Lovecraft - optam, no entanto, por uma saída que exclui o sobrenatural, mantendo a série como uma true detective story. 
A presente reflexão será dedicada, então, a uma análise minuciosa do funcionamento do insólito como estratégia renovadora da estrutura investigativa. Para tal se focará em três manifestações do insólito: (i) um insólito estrutural, ou seja, que explora alterações diretamente na organização do enredo base - com destaque para o assassinato por engano, a investigação desperdiçada e falta de punição - e na forma e temas da narrativa - fusão de gêneros, a ficcionalidade explícita e o jogo entre realidade e narrativa; (ii) um insólito temático, através do absurdo kafkiano, que é marcado como tema na introdução e acompanha os eventos fora de controle que ocorrem com um dos núcleos principais, criando um espaço labiríntico típico da vertente metafísica; (iii) e um insólito sobrenatural de fato, através do fantástico naturalizado, ou seja, em que o espanto perante a manifestação insólita é suprimido ainda que o fenômeno destoe das regras esperadas para o mundo construído.

A história de Fargo que seleciono para analisar se torna ainda um melhor exemplo se levarmos em conta os fatores que colaborariam para um possível esgotamento do modelo: é a terceira temporada de uma série em que cada temporada narra uma história independente, mas todas unidas por um mesmo espaço e temas comuns; é uma série inspirada em um filme, com o qual divide uma mesma continuidade narrativa, enredos e personagens semelhantes; é ambientado em pequenas cidades do interior, espaço marcante dos romances de enigma desde o começo da tradição detetivesca; e, por fim, é, ao menos em parte, uma narrativa investigativa, contendo todos os elementos do enredo que já em 1905 ameaçava apresentar sinais de esgotamento. 
Ainda assim - espero ser capaz de mostrar - a terceira temporada de Fargo consegue se renovar através da exploração dessas formas de insólito e mostrar-se, ao mesmo tempo, uma narrativa original, criativa e atrativa, e uma crítica metaficcional complexa de questões que dizem respeito à narrativa como um todo e, mais especificamente, à narrativa investigativa.

\section{FARGOS}

Em 1996, os irmãos Cohen lançam o filme Fargo, ganhador de dois Óscares - melhor roteiro original e melhor atriz - e muito bem recebido pela crítica de forma geral. O filme conta a história de um gerente de venda de automóveis que, diante de alguns problemas financeiros, resolve tentar aplicar um golpe no sogro, arquitetando o sequestro da própria esposa. Ambientado no interior do norte dos EUA, espaço de ordem, em que nada parece capaz de sair do esperado, o crime desencadeia uma força caótica que progressivamente vai tirando o poder de controle dos personagens, e transformando uma tentativa de estelionato em um crime muito mais complexo e violento.

Eleito por diversos críticos como um dos melhores filmes já produzidos nos EUA, Fargo carrega em si um grande potencial comercial enxergado pelos próprios irmãos Cohen, que, diante da contemporânea onda de adaptações, continuações ou releituras dos anos oitenta e noventa, colaboram na produção de uma série televisiva que carrega consigo o nome de seu magnum opus.

A série não é dirigida pelos irmãos e tampouco tenta mimetizar a estética explorada por eles no filme, mas se passa em um universo comum, fazendo com que o primeiro Fargo sirva como indicativo da 
ambientação, do tom e dos temas que se podem esperar da nova versão. Uma parte importante desse eixo temático é sumarizada já na introdução do primeiro filme dos Cohen, Blood Simple (1984), em que somos apresentados a uma espécie de inexorável lei do mundo dos Cohen: não importa quem você seja, o quão alto seja seu status, poder ou riqueza, algo sempre pode dar errado; e quando dá, você está por conta própria.

Esse elemento de caos é sempre colocando em movimento por um crime insólito. No filme, nem mesmo os criminosos conseguem entender a proposta absurda de Jerry de sequestrar sua própria esposa. É, no entanto, na série que esse potencial insólito do crime é plenamente explorado. O assassino de aluguel Lorne Malvo, figura mefistotélica, sedutora e extremamente violenta, ao passar por Bemidji, em Minnesota, acaba por esbarrar com o inofensivo vendedor de seguros Lester Nygaard. Em conversa despretensiosa entre dois desconhecidos no hospital, Nygaard reclama sobre o nariz quebrado recentemente pelo valentão da escola de sua infância e, instado por Malvo a retaliar tal ato, acaba por sugerir que o estranho mesmo fizesse isso por ele, o que, Malvo, resolve de fato fazer, assassinando o desafeto de Lester e, assim, tirando completamente do eixo a vida pacata - e algo decadente - em que se encontrava, transformando-o em cúmplice de assassinato.

O espiral de caos colocado em movimento pela figura de Malvo - ou, mais especificamente, pelo desejo de Lester - leva a região ao maior rastro de sangue visto desde uma antiga guerra entre famílias criminosas de décadas atrás. É nessa guerra que se passa a temporada seguinte. 
O que descobrimos é que o conflito entre facções também é iniciado por um crime completamente insólito: a cabeleireira Peggy Blumquist, de Luverne, também em Minnesota, voltando para casa durante uma nevasca, acaba por atropelar um homem. Desesperada com o acidente, dirige até sua casa com o corpo ainda preso ao para-brisa. Em casa, Ed, seu marido, ao ir checar o estado do carro, descobre que o homem sobreviveu. Desnorteado com a situação, o atropelado ataca violentamente Ed, que, em defesa própria, acaba assassinando o homem, que descobre, depois, ser Rye Gerhardt, o filho da família criminal que manda na cidade de Fargo. O desaparecimento do filho, em um momento de morte do patriarca da família e vácuo no poder criminal, leva a um crescimento de violência na disputa de territórios que marcará por anos as pacatas cidades dessa região.

É, no entanto, na terceira temporada, que o insólito assume centralidade, não apenas no crime inicial, mas em toda sua estética, temática e construção da narrativa. A história, como as anteriores, é desencadeada por um crime criado pela força das incontroláveis circunstâncias do universo de Fargo. Os irmãos Ray e Emmit Stussy têm uma antiga querela: a morte precoce do pai deixou como herança dois bens a serem divididos entre os filhos, um carro esportivo e uma coleção de selos; Emmit, o mais velho, convence Ray, o mais novo, a optar pelo carro, tendo em mente o valor dos selos; Emmit, a partir do patrimônio inicial da valiosa coleção, constrói uma lucrativa empresa de estacionamentos, enquanto Ray entra em decadência junto com o cada vez mais enferrujado veículo, trabalhando como medíocre agente de condicional, em St. Cloud, Minnesota. 
Ray, cansado de implorar dinheiro ao seu irmão - dinheiro que acredita ser em parte seu por direito, considerando-se enganado pelo irmão mais velho - e querendo comprar um anel de noivado para sua nova namorada, uma das ex-detentas em liberdade condicional, decide chantagear um de seus outros ex-detentos, Maurice LeFay, para ir até a casa de seu irmão e roubar o principal selo da coleção de Emmit, único ainda conservado.

O que, até então, seria a preparação para uma história de crime comum começa a se tornar um fato insólito quando LeFay deixa o papel em que havia anotado o endereço voar pela janela do carro, e, sem conseguir recuperá-lo, tenta lembrar o endereço do irmão de Ray de cabeça. Lembra-se de que a cidade continha "Eden" no nome, e que o irmão, logicamente, teria o mesmo sobrenome de Ray. LeFay, então, encontra o caminho para Éden Valley, busca em uma lista telefônica por Stussy, e, encontrando-o, vai em busca do selo. Ocorre que Emmit morava em Eden Praire, outra localidade de Minnesota. A casa que LeFay invade pertence, assim, a outro Stussy. $\mathrm{Na}$ busca por um selo inexistente em uma localidade equivocada, acaba por matar sua vítima e fugir.

A vítima, um senhor de idade, era o padrasto de Gloria Burgle, chefe de polícia de Eden Valley em processo de incorporação por uma agência maior, prestes a perder seu cargo. Burgle, diante do aparente desmotivado crime, que nada parecia a um assalto comum, já que a casa estava completamente vasculhada e nada de valor havia sido levado, começa uma investigação mais profunda dos motivos do assassinato, partindo da equivocada possibilidade de que haveria uma razão para alguém querer assassinar Ennis Stussy. 
O outro irmão, alheio a todo esse problema, vive também uma desestabilização com a chegada de V. M. Varga à região. Varga, como Lorne Malvo, é a personificação do caos em contraste com a ordem impecável da cidade interiorana. Emmit havia pedido um empréstimo de um milhão de dólares a uma empresa de capital privado para salvar seu negócio durante a crise e, agora, Varga vinha para informar-lhe que o dinheiro que haviam concedido não era um empréstimo, mas um investimento: usariam a empresa de Emmit para cometer fraude fiscal.

Cada tentativa de Emmit de dissociar-se de Varga o empurra um passo mais para o fundo do esquema inescapável que o criminoso vai montando na empresa, prendendo-o em um labirinto angustiante do qual, como veremos, não consegue escapar nem se entregando à polícia.

Estabelece-se, então, um jogo complexo entre três núcleos narrativos. Em um lado, Ray e sua namorada, Nikki Swango, tentando roubar e extorquir o dinheiro de Emmit; em outro, Gloria tentando investigar o impossível caso do assassinato de Ennis; e, por último, Emmit tentando, ao lado de seu fiel associado, Sy Feltz, escapar da organização criminal representada por Varga.

Conforme o enredo avança, esses núcleos vão se chocando, com Gloria descobrindo informações sobre Varga, Emmit assassinando Ray e Nikki buscando vingança contra Varga e Emmit. Como as demais histórias de Fargo, a violência e o crime vão escalando conforme os personagens perdem o controle da própria situação que criaram e a população das pequenas cidades envolvidas no evento vai assistindo absorta seu ordeiro e cotidiano espaço se tornar lugar dos mais chocantes eventos. 


\section{A NARRATIVA INVESTIGATIVA METAFÍSICA}

Como disse anteriormente, pretendo explorar, aqui, três aspectos distintos da manifestação do insólito na obra: um estrutural, ligado à desconstrução das convenções do gênero e explicitação da ficcionalidade e da materialidade, um temático, ligado ao absurdo kafkiano e a impotência perante forças desconhecidas, e um relativo à manifestação do sobrenatural, ligado ao uso do um fantástico naturalizado jogando com as fronteiras real/ficcional e fato/narrativa.

Minhas observações, neste texto, enquadrarão Fargo em uma vertente pós-moderna da narrativa investigativa - que, no entanto, encontrará raízes ainda no início do gênero -, geralmente chamada pela crítica anglófona de metaphysical detective story ${ }^{4}$ - também conhecida como anti-detective story/fiction, desconstrutive mysteries ou postmodern mystery, entre outras -, uma união improvável entre a tradição da narrativa investigativa, claramente associada aos gêneros populares, de entretenimento - logo vista, geralmente, pela crítica tradicional, como uma forma menor de literatura -, e as preocupações e experimentalismos próprios da literatura moderna, em geral, elitista e avessa ao apelo popular que o gênero criminal geralmente oferece.

Essa vertente é marcada, segundo Patricia Merivale e Susan Elisabeth Sweeney, por seu interesse nos "profundos questionamentos que levanta sobre narrativa, interpretação, subjetividade, a natureza da realidade e os limites do 
conhecimento $^{5 \prime \prime}$ (1999, p.1 - tradução nossa). As autoras definem tal vertente como:

[U]m texto que parodia ou subverte as convenções da tradicional história de detetives - tais como encerramento narrativo e o papel do detetive como substituto do leitor - com a intenção, ou ao menos o efeito, de questionar sobre os mistérios do ser e saber que transcendem as meras maquinações do enredo de mistério6. (1999, p.2 - tradução nossa)

Nesse objetivo duplo de, por um lado, revelar as amarras das convenções da narrativa investigativa através da paródia/ subversão, e, por outro, de utilizar o mesmo gênero para propor reflexões mais amplas sobre narrativa, realidade, interpretação e subjetividade, essa vertente lança mão de alguns temas comuns, aos quais tentarei me ater nas observações feitas ao longo deste artigo. São elas:

(i) A figura do detetive vencido, descontruindo qualquer possibilidade de encará-lo com um herói na narrativa;

(ii) A sensação de aprisionamento em um mundo/cidade/ texto labiríntico;

(iii) A revelação da materialidade do texto através da autorreferencialidade, do mise en abyme, dos artifícios textuais etc.;

5 No original: "The metaphysical detective story is distinguished, moreover, by the profound questions that it raises about narrative, interpretation, subjectivity, the nature of reality, and the limits of knowledge".

6 No original: "A metaphysical detective story is a text that parodies or subverts traditional detective-story conventions-such as narrative closure and the detective's role as surrogate reader-with the intention, or at least the effect, of asking questions about mysteries of being and knowing which transcend the mere machinations of the mystery plot". 
(iv) A ambiguidade, ubiquidade ou falta de sentido nas pistas e evidências;

(v) O problema da identidade - perdida, duplicada, roubada, falseada, trocada etc;

(vi) A ausência, circularidade ou fracasso de qualquer tipo de encerramento para a investigação (cf. MERIVALE; SWEENEY, 1999, p.8).

\section{O INSÓLITO E AS CONVENÇÕES DA NARRATIVA INVESTIGATIVA}

O primeiro elemento a chamar a atenção, quando lidamos com Fargo, é o foco em sua materialidade, já presente no aviso inicial, um dos poucos elementos estruturais que é integralmente mantido entre o filme as temporadas da série: “Essa é uma história real. Os eventos aqui representados ocorreram em Minnesota em [ano em que se passa a história, variando entre filme, 1987, primeira temporada, 2006, segunda, 1979, e a terceira, 2010]. A pedido dos sobreviventes os nomes foram alterados. Por respeito aos mortos, 0 resto foi contado exatamente como aconteceu".

A frase claramente mimetiza uma convenção do gênero true crime. Enquanto a vertente detetivesca do gênero criminal manteve, por muito tempo, pouco contato com essa estratégia de aproximação do real $^{7}$, a vertente centrada em criminosos

7 A discussão é muito ampla para ser feita aqui, mas o grau de artifício que se impunha aos romances de enigma e a estetização quase excessiva que marca o hard-boiled - fora a necessidade de construção da personagem heroica enfraquecida por uma necessidade de paridade com o contexto de produção -, afastava o gênero de uma necessidade e mesmo de uma possibilidade de explorar a rentável etiqueta editorial true crime para essas obras. Já nas narrativas centradas nos criminosos, seu uso é abundante ao ponto de definir-se como uma de suas principais características, das narrativas de Newgate à Urban fiction contemporânea. Para um aprofundamento nessa questão, (cf. SASSE, 2019, p.140). 
explorou abundantemente seu uso, partindo da popularidade já presente de crimes reais para, então, construir histórias que dessem a profundidade que lhes faltava na simples notícia. De fato, se voltarmos em A sangue frio, de Truman Capote - autor responsável por revigorar a vertente true crime nos anos 60, renomeando-o de non-fiction novel - veremos mais que o uso dessa estratégia, mas uma grande proximidade com o enredo, sobretudo do primeiro filme: dois criminosos, uma pacata cidade do interior, um plano que não sai como o esperado, crimes horrendos que abalam aquela sociedade.

A estratégia da etiqueta true crime, no entanto, é construída para fortalecer a proximidade com o contexto do leitor, transmitir a mensagem que o mundo narrado é o mundo real e que as ameaças que espreitam as páginas da obra também se encontram fora dela. Esse não é absolutamente o objetivo de Fargo, sobretudo na terceira temporada, essa etiqueta é completamente esvaziada de sua função convencional, servindo apenas para aumentar a sensação de desconcerto entre a expectativa criada no espectador por ela e completa quebra dessas convenções.

A desconstrução começa por uma escolha peculiar: normalmente, esse tipo de aviso precede o início da história apenas. $\mathrm{Na}$ série, cada episódio repete exaustivamente a mensagem, ajudando a esvaziar seu impacto, como se a série insistisse, suspeitamente, em convencer o leitor de sua veracidade. Depois, seu uso se torna ainda mais paradoxal diante dos acontecimentos insólitos da narrativa, que transmitem ao leitor a mensagem oposta: isso não é uma história real, é pura ficção. 
Diante dessa tensão, a frase de início deixa de ser um aviso e se torna uma provocação que marca um dos temas centrais de Fargo como um todo: a tensão entre realidade e narrativa, a maneira como discursos podem mudar o que percebemos enquanto real, um real moldável, flexível, fluído. Nas palavras de Varga: “A percepção da realidade se torna realidade" (HAWLEY, 2017, episódio 06, 04'06").

Varga, assim como Lorne, é um forasteiro e, como Bauman nos relembra em $\mathrm{O}$ mal-estar na pós-modernidade, esse forasteiro tem:

[o] impacto de um terremoto... [...] despedaça a rocha sobre a qual repousa a segurança da vida diária. Ele vem de longe; não partilha as suposições locais - e, desse modo, "torna-se essencialmente o homem que deve colocar em questão quase tudo o que parece ser inquestionável para os membros do grupo abordado" (BAUMAN, 1998, p.19)

Esses personagens, por seu próprio comportamento, colocam em que xeque as convenções sociais que marcam a vida da cidade interiorana. A polidez típica de seus moradores não encontra formas para lidar com a honestidade brutal e completa falta de constrições sociais que pautam o comportamento desses forasteiros. Da mesma forma em que abalam as convicções dos moradores, agem também sobre a convicção do espectador em relação à veracidade da própria história.

Varga destoa completamente do que se espera de um personagem realista de um true crime. É construído de forma excessiva, com forte influência do gótico, como já podemos perceber na insólita caracterização de sua aparência: a pele doentia, o olhar morto, os dentes completamente apodrecidos, a roupa velha e desbotada. Varga está na fronteira da aparência de um morto-vivo. 
Seu comportamento é igualmente repulsivo em excesso: come compulsivamente apenas para vomitar tudo em seguida; gosta de cutucar seus dentes podres com um palito de ferro, chegando a ferir a gengiva muitas vezes, manchando sua boca de sangue; e chega, em certo momento, a obrigar um dos personagens a beber sua urina apenas para intimidá-lo.

Essa repulsa inspirada pela aparência e comportamento de Varga entra em contraste com a fascinação que seus discursos exercem. Há, na fala do personagem, uma profunda teatralidade, que o torna ainda mais distante do cenário realista que está à sua volta. Para introduzir cada ideia sua, conta uma história ilustrativa de início, marcando sua função enquanto construtor de narrativas logo, segundo sua lógica, construtor de realidades. Vale marcar, no entanto, que a maior parte das suas histórias são completamente infundadas ou absurdas, mas sua convicção e eloquência as tornam inquestionáveis para a maior parte dos personagens, cimentando a "percepção da realidade" que ele constrói. Um dos poucos personagens capazes de ver além desse poder é Gloria, que representa sua antítese, não se deixando seduzir pelos poderes das palavras vazias.

A problematização da etiqueta true crime é secundária na problematização do gênero se comparada com a construção do personagem e do arco de Gloria ao longo da história. Retomando, assim, os temas recorrentes da vertente metafísica, podemos explorar a desconstrução da figura do detetive, da investigação e da possibilidade do encerramento do caso - aspectos fundamentais para a narrativa investigativa tradicional - através da detetive Gloria Burgle. 
Enquanto o vilão da história de Fargo representa as forças de caos que agem sobre as pequenas cidades de Minnesota, Burgle representa o mais resistente pilar da ortodoxia num mundo cujas transformações são cada vez mais velozes, sucumbindo lentamente à inexorável força de tais mudanças e perdendo, nesse processo, suas convicções, sua identidade e chegando a questionar sua própria existência.

O primeiro confronto de Burgle se dá em seu casamento. A detetive, que casara com o primeiro namorado de ensino médio, começa a história em um processo de divórcio. O marido a havia abandonado para morar junto com outro homem, fato com que Burgle, apesar de compreensiva, demonstra dificuldade para entender e para explicar ao filho. Confiante na velha ordem familiar, Gloria tenta sustentar uma relação entre seu padrasto, Ennis Stussy, e seu filho, para dar ao menino a possibilidade de ter um avô, já que o pai biológico dela estava morto. Ennis é um homem desagradável e pouco se esforça para mudar, mas Gloria faz o sacrifício de tolerá-lo para manter essa ordem, que acaba Ihe sendo arrebatada ainda no primeiro episódio, com o assassinato de seu padrasto.

O que parece, a princípio, representar uma polaridade típica de narrativas investigativas mais tradicionais, a ordem que Burgle representa em oposição a Vargas, longe de lhe conferir um caráter estoico, heroico ou superior, aumenta sua impotência perante essas forças de mudança.

Disposta a investigar o caso do assassinato de Ennis, Gloria começa a rastrear os traços de LeFay - que já havia sido, nesse ponto, assassinado por Ray e por Nikki após uma tentativa de 
extorsão ao casal -, mas é logo impedida pelo surgimento da figura de Moe Dammick. Reforçando a mensagem da velha ordem abrindo espaço para as mudanças imparáveis, a delegacia de Gloria está sendo absorvida por uma maior, o que faz com que seu posto de chefe de polícia seja transmitido a um novo chefe, que é Moe.

O primeiro conflito entre ambos é um conflito entre tradicional e moderno. Moe percebe que não há computadores na delegacia em pleno ano 2010 e ao decidir questionar Gloria sobre isso, vemos a tensão entre essas visões de mundo:

Moe: Você não gosta de computadores?

Gloria: Não é que eu não gosto. Não gosto, mas não... $O$ jeito antigo funciona bem. Datilografar um boletim, mandar via telex.

Moe: Você sabe em que ano estamos, certo? O futuro. Não usamos... Quem ainda usa telex?

Gloria: Então é por isso que ninguém me responde. $[\ldots]$

Moe: Não estamos nos anos 50 onde ninguém tranca as portas.

Gloria: As pessoas não trancam as portas. Aqui não.

Donny [outro policial, amigo de Gloria]: Embora talvez comecem depois do que aconteceu com Ennis. (HAWLEY, 2017, episódio 02, 15'25")

Moe, força dinâmica, pragmática e contrária à velha ordem de Gloria, será responsável por impedir a ação investigativa da detetive. Vendo o caso de Ennis como um típico latrocínio, não tem interesse em encontrar um significado maior, capaz de preencher as lacunas inexplicáveis do crime - a casa revirada, 
nenhum bem levado, uma página rasgada de uma lista telefônica de uma loja de conveniência próxima como endereço de Ennis - e, assim, reestabelecer a ordem da comunidade.

Na busca pela solução de um mistério e o reestabelecimento da ordem, Gloria se encaixa, em caráter e objetivos, perfeitamente no modelo do detetive clássico, mas tal caracterização tem como função simplesmente acentuar a desconstrução dessa figura. Isso se torna mais explícito do que nunca no terceiro episódio, "O princípio da não-contradição".

Esse episódio se constrói quase completamente isolado do enredo, o que o torna muito peculiar. Diferente de todos os demais, é inteiramente centrado no núcleo de Gloria e único episódio em que vemos analepses, que intercalam a investigação do passado de Ennis em Hollywood pela detetive com a história trágica da juventude de seu padrasto.

O episódio, abundante em simbolismo, metáforas e referências, intercala ainda esses focos narrativos com a leitura, em mise en abyme, de trechos do romance fictício O planeta Wyh, de Thaddeus Mobley. O título, em inglês, joga com a sonoridade da palavra inglesa "why", como explicitado algumas vezes no diálogo dos personagens. Dessa forma, The Planet $W y h$, indicaria também o planeta do "por quê", ou da busca pelo significado, mas, ao mesmo tempo, um "por quê" equivocado, pela inversão das letras y e $h$, como o equívoco de letras entre Ennis e Emmit, ou de palavras entre Eden Valley e Eden Praire, que marca o insólito destino do padrasto de Gloria. O romance narra a história de um inofensivo robô que colide em um planeta ainda em seus primeiros passos de 
existência e, impossibilitado de sair, assiste às inúmeras mudanças da civilização, da ascensão do homem ao declínio da civilização, só sendo capaz de falar uma única frase: "Eu posso ajudar", repetida nos mais diversos contextos e sempre sem que ninguém o ouça ou se importe com ele.

A investigação, mesmo através de pistas completamente equivocadas ${ }^{8}$, conduz a um crime real. Ao longo do episódio, a detetive descobre que Ennis foi Thaddeus no passado. Após ganhar o prêmio literário, havia sido enganado por dois estelionatários, que o fizeram gastar todo o dinheiro recebido. Após descobrir, Ennis, furioso, acerta o golpista na cabeça e, acreditando o ter assassinado, larga tudo para trás, muda de nome e se muda para o interior do país, virando Ennis Stussy - nome retirado dos fabricantes da privada do motel, para aumentar o triste acaso de sua escolha.

Essa descoberta, no entanto, apenas serve para mostrar a completa desconexão daquele mundo com o caso - em consonância com a falta de sentido nas pistas e evidências elencada anteriormente como característica típica da vertente metafísica. O homem golpeado sobrevivera e estava decrépito em um hospital, incapaz de qualquer ato. A atriz da foto, parceira do golpista, era uma arrependida e amargurada garçonete de restaurante. E Gloria, assim como o robô, tenta em vão ajudar, apenas podendo ser testemunha de mais um exemplo das forças incontroláveis do caos diante de sua incapacidade de conferir sentido ao mundo. 
O episódio, apesar de muito bem construído, é, do ponto de vista do arco investigativo, completamente dispensável. Sua colaboração é apenas a eliminação de uma hipótese que já sabemos de antemão equivocada, o que nunca mereceria o mesmo espaço e destaque nas narrativas tradicionais do gênero. A natureza desse episódio estabelece uma relação metonímica com um objeto encontrado no quarto do motel em que Gloria se hospeda durante a investigação: uma caixa com um pequeno interruptor que, ao ser acionado, faz com que uma mão mecânica saia da caixa e o desative. É um mecanismo complexo para algo aparentemente despropositado, uma sátira da própria estrutura do episódio e, por extensão, da narrativa investigativa.

A investigação central da história não tem melhor resultado. $\mathrm{O}$ insólito crime quase impossibilita um bom processo lógico e, quando a detetive consegue qualquer progresso é freada pelo pragmatismo de seu novo chefe, que a impede de continuar a investigação do que acredita ser apenas uma triste coincidência. A maior parte dos avanços da investigação acabam se dando por acasos, como o acidente de carro entre Ray e Sy, ajudante de Emmit, que faz com que uma policial de tráfego de outra cidade acabe compartilhando informações dos suspeitos com Gloria por motivos completamente diferentes, mas que acabam sendo cruciais na investigação.

Gloria, mesmo quando recebe um Emmit desesperado e confuso, querendo se entregar à polícia para fugir das garras de Varga, confessando a rixa com seu irmão e as tentativas do roubo do selo - o que resolvia o caso de Ennis - e sobre o acidental assassinato de Ray em uma briga dos dois, é incapaz de transformar 
sua investigação em justiça. Varga, sua força oposta - que domina o poder do discurso pós-moderno de remodelação da verdade, enquanto, Gloria, símbolo da velha ordem, acredita ainda que os fatos são capazes de falar por si sós e levar um homem a ser corretamente julgado e punido -, assassina mais dois Stussys de cidades próximas e constrói, através de uma falsa confissão por um mendigo subornado, a ideia de um serial killer que sofreu no passado na mão de um Stussy e estava, agora, empenhado agora em se vingar do sobrenome. Moe, entusiasta da modernidade em oposição à Gloria, acaba sendo também o mais fiel adepto às verdades construídas por Varga, acreditando imediatamente na história do assassino serial e encerrando a investigação da detetive com a errônea prisão e liberação de Emmit.

Mesmo quando Nikki, única à altura no domínio das forças do caos, rouba e entrega o dossiê que incriminaria Varga - não pelos assassinatos, mas pela fraude que cometia na empresa de Emmit -, resolvendo o que a detetive é completamente incapaz de fazer, Varga escapa sem dificuldades, mantendo suas contas milionárias em paraísos fiscais.

Encontrado anos mais tarde tentando cruzar as fronteiras do país, Varga é conduzido para interrogatório por uma Gloria que havia largado a vida no interior e trabalhava agora no Departamento de Segurança Interna. Ali ocorre o embate final entre os dois. Longe de um confronto convencional da vertente investigativa, que envolveria tentativas de fuga e perseguição, o embate é discursivo, entre a defesa de dois pontos: a realidade é um fato sólido tal como Gloria, representante da velha noção de 
verdade, defende, ou um discurso moldável, como os que Varga, símbolo da nova ordem, utiliza para construir essa realidade?

Varga: Você conhece o ditado russo que diz: "O passado é imprevisível"?

Gloria: Tenho certeza de que inventou isso ${ }^{9}$.

Varga: Talvez. Mas qual de nós pode dizer com certeza o que aconteceu, aconteceu de verdade, e o que é simplesmente boato, informação falsa, opinião?

Gloria: Uma fotografia é considerada prova no tribunal.

Varga: Mas fotos podem ser fabricadas. Os olhos podem enganar. Nós vemos o que acreditamos, não o contrário.

Gloria: Seis pessoas mortas, incluindo um policial estadual. U\$ 200 milhões não explicados. Esses são fatos. E você estava no meio dessa bagunça. $\mathrm{O}$ que mais preciso ver?

Varga: Um homem acorda um dia e decide matar quatro homens acima de certa idade, todos com o mesmo sobrenome.

Gloria: [Ri] Isso não aconteceu.

Varga: Mas se provas forem obtidas, se confissões forem feitas, se uma condenação for dada por um tribunal, esse acontecimento se torna como as rochas e os rios, e argumentar que isso não aconteceu é argumentar contra a própria realidade. (HAWLEY, 2017, episódio 10, 43'25')

Em uma história que seguisse as convenções da narrativa investigativa tradicional, Varga, grande nêmese da detetive, deveria

9 Essas duas primeiras frases reforçam a ideia explorada antes das anedotas inverossímeis de Varga e a capacidade de Burgle de não ser seduzida por elas. 
ser punido: ou prisão ou morte - nunca causada voluntariamente pelo próprio detetive, claro. No entanto, como anteriormente vimos, é uma marca recorrente da vertente metafísica a suspensão desse veredito final.

O embate entre os dois prossegue até o momento em que chegam a um impasse final: Gloria, confiante nos fatos, afirma que em alguns minutos um policial entrará na sala, algemará Varga e o levará para a prisão, espelhando a expectativa confiante do leitor de romances detetivescos tradicionais; Varga, no entanto, Ihe diz o oposto, que algum superior entraria na sala e diria que ele está liberado para ir, e ele sumiria no mundo novamente - o que também cumpriria, de certa forma, as expectativas de certas vertentes centradas em criminosos. Não há mais conversa para ambos, resta esperar para descobrir qual dos dois aspectos do mundo prevaleceria: a verdade, a ortodoxia, a justiça e os sentidos estáveis de um lado; o discurso, a inovação, a aparência e os sentidos fluidos do outro.

A obra, claro, se encerra sem oferecer tal resposta, deixando em suspenso qualquer certeza possível. É curioso notar, ainda, que nesse encerramento, a obra desvela plenamente sua ficcionalidade na representação da cena: Varga, após encerrar o confronto, entendendo que não havia mais o que ser discutido, fecha os olhos e diz "Adeus"; a iluminação que recai sobre o personagem, então, vai progressivamente sendo suprimida, como num teatro em que se apagam os holofotes, deixando apenas a luz de fundo.

Não existe explicação possível, dentro da verossimilhança da história, que sustente a possibilidade daquela reação insólita 
do personagem e o ainda mais insólito apagar das luzes com duas pessoas na sala. Essa cena só pode fazer sentido quando a entendemos não como um evento próprio da narrativa que está sendo contada, mas como um signo do ato de narrar em si, que, em oposição à constante afirmativa de que se trata de uma história real contada sem nenhuma alteração dos eventos, ratifica sua ficcionalidade.

Essa exploração da materialidade, terceira característica que elencamos como própria da vertente metafísica, é vista, ainda, de forma bem explícita no quarto episódio, "O problema da saída estreita". Esse episódio, diferente de todos os demais, começa com um voice over, que retoma a introdução da composição musical de Pétya i volk, "Pedro e o lobo", de Sergei Prokofiev. A obra do compositor soviético narra a história infantil associando os instrumentos a personagens específicos da obra, e a introdução é responsável por apresentar essas associações, como Pedro com o naipe de cordas e o lobo com a trompa.

Fargo desloca a introdução da obra de Prokofiev para o começo do quarto capítulo, criando agora uma nova camada de associações. Se na obra original cada instrumento representa um dos personagens do conto infantil, agora, cada personagem do conto infantil representa, também, um personagem da trama: o pássaro, interpretado pela flauta, simboliza Emmit, sempre ingênuo e simpático; o pato, interpretado pelo oboé, é o melancólico e desastrado Ray; a ardilosa gata, através do clarinete, é a igualmente esperta e perigosa Nikki; o fagote dá voz ao avô, associado a Sy, rabugento e ultrapassado; os tímpanos dos caçadores são associados aos capangas de Varga e este é o vil 
lobo tocado pela trompa; por último, Pedro, através das cordas, é associado com a detetive Burgle, curiosos e corajosos, sem medo de enfrentar o lobo.

O episódio, então, toma como trilha sonora trechos da peça musical arranjando os instrumentos de acordo com a aparição dos personagens em cena. Ainda que o enredo de Fargo não espelhe o do conto infantil, esse artifício narrativo adiciona novas camadas de sentido ao texto do episódio, revelando a exploração de sua materialidade como forma de construção de novos significados, inserindo uma quase arbitrária - nem a série nem o episódio encaixam plenamente no enredo de "Pedro e lobo" - chave de leitura da obra, que mesmo imperfeita, permite uma multiplicação de sentidos.

Com isso, acredito ter sido possível dar conta de mostrar, ainda que brevemente, esse insólito estrutural, representado pela quebra das convenções e pela sátira de seus elementos, dando conta de uma associação com as características da vertente metafísica que dizem respeito ao detetive, à investigação, ao encerramento e ao uso da materialidade. Restam agora o segundo - o espaço labiríntico e aprisionador - e o quinto - a questão da identidade pontos a serem analisados, cada um centrado em um dos outros usos do insólito na obra.

\section{O ABSURDO KAFKIANO, O ESPAÇO LABIRÍNTICO E O MAL UBÍQUO}

A terceira temporada de Fargo começa com uma cena que não encontra nenhuma relação espacial ou temporal com os acontecimentos que ocorrerão ao longo da obra. Não há nenhuma conexão aparente, tampouco, com os eventos que ocorrerão, não 
se tratando de nenhuma analepse ou prolepse que explique algum outro elemento da história. Sua única função é servir como uma espécie de epígrafe: um fragmento que precede o início da obra e lhe serve como símbolo, marcando o tom que predominará ao longo da história, seu eixo de sentidos, seu tema central. Tal ferramenta é mais um bom exemplo da exploração dessa materialidade na construção dos sentidos da história que viemos trabalhando. No entanto, mais central para nossa análise, é entender que chave interpretativa nos oferece esse prólogo.

A cena se passa em um cinzento despacho da Berlim ocidental de 1988. A sala está em penumbra e neva do lado de fora. Um homem detido é trazido à presença de um oficial do governo para interrogatório. As roupas indicam que o homem foi retirado de casa às pressas. Seu rosto dá indícios de que nenhuma explicação lhe foi dada. O oficial, Horst Lagerfield, termina tranquilamente seu lanche enquanto o homem detido Ihe encara com confusão, depois inicia seu interrogatório por uma pergunta simples: "Seu nome é Yuri Gorka?" (HAWLEY, 2017, episódio 01, 02'08'”). O interrogado, Jacob Ungerleider, responde que não e, aliviado, percebe ser tudo um mal entendido.

No entanto, os registros indicam que o morador do endereço de Jacob é Yuri Gorka, logo, numa lógica bem simples e direta, Horst afirma que ele está mentindo sobre sua identidade. A situação se torna mais confusa quando o oficial diz que ele é um imigrante ucraniano de vinte anos, quando o interrogado claramente tem algo em torno do dobro disso. Ele indica que talvez seja por que mora há pouco tempo no endereço, mas o oficial o interrompe e Ihe apresenta o dilema: "Isso é um problema, você entende? Porque 
para você estar certo, o estado tem que estar errado. É isso o que está dizendo? O estado está errado?" (Episódio 01, 02’08'”).

Em uma lógica cruel, Horst encurrala o interrogado: ou acusa o estado ou se incrimina de algo absurdo. Diante do silêncio, o oficial dá prosseguimento com o interrogatório e lhe pergunta sobre o assassinato de sua namorada, Helga Albracht. Novamente Jacob tenta explicar o mal-entendido, mas dessa vez esbarra em uma triste coincidência: sua esposa, e não namorada, viva pelo menos até o momento que ele foi retirado de casa, também se chama Helga, ainda que com outro sobrenome. Jacob sente que sua possibilidade de defesa míngua perante o absurdo e Horst arremata:

Eu Ihe mostrei um cadáver, gelado e azul. Eu vi o cadáver com meus próprios olhos. A morte dela é um fato. O que você está me dando são palavras. Essa "esposa", que está "viva", um "sobrenome diferente". Isso se chama "história". E não estamos aqui para contar histórias. Estamos aqui para contar a verdade. (HAWLEY, 2017, episódio 01, 05'12")

Jacob está paralisado diante da situação. A realidade parece invertida: suas verdades se tornaram história e o que parecia ser um completo mal-entendido se torna a pura realidade para o interrogador. Essa fala, que encerra a cena introdutória, estabelece o eixo temático da temporada: o embate entre realidade e discurso, a impotência do homem de argumentar em prol dos fatos em um mundo em que história e verdade se tornam plenamente intercambiáveis.

O cenário, a ambientação, a acusação e a figura confusa, angustiada e impotente de Jacob, remetem claramente a $O$ processo, de Franz Kafka, em que K desperta sendo acusado de 
um crime que desconhece completamente e que ninguém é capaz de informar-lhe. Ambos são personagens que tentam aplicar o bom-senso a um mundo cuja lógica foge completamente à sua compreensão. Um mundo absurdo, de regras insondáveis, em que, progressivamente, os personagens vão afundando e, quanto mais tentam se debater, mais presos ficam.

No episódio em si, esse absurdo é encarnado pelos personagens Varga e Moe. Varga é aquele que domina plenamente a lógica desse mundo absurdo, e é capaz de moldá-la a seu bel prazer. Jamais empunha uma pistola na série. Sua arma é sua voz: mesmo sob a mira de Emmit, ameaçado de morte, controla a situação contando uma de suas histórias, sempre absurdas. Já Moe é aquele que, complemente destituído de pensamento crítico, é incapaz de duvidar das palavras, daquilo que lhe é apresentado como verdade - e, por isso, se torna o mais eficaz executor da lógica de mundo de que Varga se aproveita.

Emmit e Gloria, assim, assumem o papel antes dado a Jacob: serão a impotente voz do bom senso diante de um mundo absurdo. Emmit, do dia para a noite, se vê jogado em uma situação labiríntica: cada passo que dá em busca de uma saída o leva a penetrar mais a fundo no problema. No episódio final, quando percebe que mesmo sua saída mais desesperada havia sido, desde o princípio, arquitetada e controlada por Varga, Emmit desabafa: "Como uma saída de emergência que leva a outro incêndio" (HAWLEY, 2017, episódio 10, 21'47').

A obra explora de forma algo cômica - ainda que de humor negro - a incapacidade de Emmit fazer qualquer coisa para 
impedir o avanço de Varga. Acostumado a um mundo de rígidas leis, jurídicas e sociais, Emmit se vê sem armas quando Varga, o forasteiro, aquele que não está ligado às leis da comunidade, mas que a as coloca em xeque, ignora seus educados pedidos e sutis ameaças legais. Em suas palavras:

Eu já lhe disse o que eu gosto nesse lugar, Minnesota? É tão perfeitamente e sublimemente brando. Já esteve no Danúbio? Ou em Gansu? E o continente africano... Esqueça. Norte e Sul. Anarquia. E sim, você ainda pode achar estabilidade relativa nos brutais estados-nação, Coreia do Norte... Putin fez coisas ótimas na Rússia. Você tem que saber quem subornar. Mas remunerações constantes e pequenas ameaças cansam... [...] Veja, esse é o problema dos americanos. Vocês assistem muitos filmes, e pensam que um acordo pode ser mudado, mas não pode. Somos parceiros agora, e isso é tudo. [...] Aí. Aí está. Agora vocês estão entendendo. A realidade inevitável. Vocês estão presos. (HAWLEY, 2017, episódio 02, 45’29")

A cada dia, Varga expande seus domínios sobre a vida de Emmit um pouco mais. Se no começo apenas se apresenta como parceiro do empresário, pouco depois estaciona um centro de operações em um de seus estacionamentos, depois toma uma ala da sede de sua empresa, arrebata o escritório de Sy e quando Emmit dá por si, Varga caminha livremente por sua própria casa.

Do lado de Gloria, o absurdo se dá não pela ação de Moe, mas por sua completa imobilidade. Não importa que provas a detetive leve para o novo chefe, ele não aceita a possibilidade de fazer um raciocínio que não seja completamente óbvio e linear. Para ele, a explicação mais provável é a verdadeira e, no caso 
Stussy, a explicação mais provável é a pura coincidência entre os sobrenomes de Emmit e Ennis, nada mais. Quando Emmit se entrega e confessa, o que tornaria impossível manter ainda a mesma lógica da coincidência, Varga reformula a narrativa e Moe adere à nova versão sem pestanejar. Ignorando toda a complexa rede de evidências, confissões e conexões construída por Gloria, Moe prende o sem-teto que, subornado por Varga, confessa ter assassinado Ennis, Ray e outros dois Stussy de cidades próximas, por ter problemas de infância com alguém de mesmo sobrenome.

Nesse momento, Gloria vê sua completa derrota como detetive. Não importa o quão racional seja sua investigação, o mundo a sua volta não é lógico, nem mesmo seus colegas de trabalho o são, muito menos o sistema judiciário. Como a mitológica Cassandra, a detetive avisa sem jamais ser ouvida, como o robô de Mosbley, oferece ajuda, sem jamais ajudar. Tal fato afetará profundamente sua própria visão de si, como veremos no próximo tópico.

Antes de prosseguir, no entanto, vale ressaltar o papel desse absurdo na construção da ameaça criminal própria do gênero. E. M. Wrong, na introdução da coletânea de contos Crime and detection, faz um comentário curioso sobre a construção do antagonista dos romances de enigma: segundo o autor, grandes organizações criminosas, ainda que fossem temas atrativos aos escritores do gênero, eram péssimas escolhas (cf. WRONG, 1947, p.26). Parte de sua justificativa se dá pela incapacidade do detetive de lidar com um problema que foge à esfera da ação individual - de que vale investigar um crime individual quando o problema está enraizado no sistema? Além disso, Wrong argumenta que um mestre criminal capaz de articular uma rede desse nível não teria por que seguir o 
caminho do crime, podendo se tornar rico e poderoso na política ou no ramo empresarial.

Wrong escreve tal texto em 1926, poucos anos depois a ficção de gângsteres viria provar que seu ponto não estava necessariamente certo. Sua lógica, como de Gloria, é válida, mas aplicável a um mundo que já deixava de existir em sua época. No mundo do capitalismo tardio, a real ameaça criminal não é o criminoso ocasional - Nikki -, o ladrão - Maurice LeFay -, mesmo o assassino - Emmit. É justamente o empresário, o bilionário, o homem cujas ações estão muito além do alcance da justiça, pois ele as molda de acordo com suas vontades.

Essa nova forma de criminoso, muito bem explorada por Fargo, cria uma curiosa representação dos medos relacionados ao crime na pós-modernidade. Apresenta-nos uma ameaça dispersa e sublime, porque insondável, inatingível, imprevisível. Uma força capaz de remodelar a própria realidade através da construção de novas narrativas, cimentadas pela compra de testemunhos, forjamento de provas e suborno de tribunais. Em sua forma última, uma oligarquia, que se funde ao poder do estado, tornando-o tão absurdo e assustador quanto o poder que vimos no caso de Jacob e Horst.

É esse poder ubíquo que torna tão labiríntico o espaço de Gloria e, sobretudo, de Emmit. A detetive percebe a magnitude desse poder, quando, no caso de Emmit, o criminoso confesso é liberado mesmo contra a sua vontade e contra todas as provas obtidas até então. Emmit já o experimenta desde o início: cada aspecto de sua vida parece vigiado e controlado por Varga. Ainda no início 
da narrativa, o chefe criminal avisa ao empresário que já conhecia todo o funcionamento da empresa, porque havia se infiltrado nos sistemas eletrônicos há tempos.

A tecnologia funciona como uma das maiores aliadas da ubiquidade desse poder. Varga se mostra quase omnisciente graças a seu aparato de vigilância, que inclui escutas telefônicas, hackers e mesmo a simples pesquisa em redes sociais. Esse controle vasto solidifica, assim, a segunda característica da vertente metafísica, esse espaço labiríntico do qual os personagens tentam em vão escapar.

Sua única resistência acaba sendo Gloria, que, avessa aos avanços da tecnologia, não existe virtualmente. Sem facebook, sem rastros em mecanismos de pesquisa, nem mesmo sua delegacia tem muitas informações online, o que dificulta profundamente o trabalho de Varga. Essa vantagem, no entanto, é ambígua: se, circunstancialmente, é positiva para evitar a ação do criminoso contra ela, no geral, Ihe traz apenas uma sensação de invisibilidade, de exclusão do mundo.

É justamente essa sensação que nos leva à última característica da vertente metafísica a ser analisada aqui. Veremos, assim, como sua angústia existencial e sua crise de identidade, problemas tão importantes quanto os crimes investigados, é representada através do peculiar uso do fantástico naturalizado.

\section{O FANTÁSTICO NATURALIZADO E A JORNADA PELA IDENTIDADE}

Antes de iniciarmos esse tópico, vale lembrar o problema que o fantástico naturalizado representa para o esquema conceitual de Todorov em Introdução à literatura fantástica. O 
teórico búlgaro trabalha o conceito de fantástico sempre através da tensão entre dois polos do espectro metafísico da obra: ou o fenômeno fantástico é explicado racionalmente, enviando a obra para o campo do estranho, do espaço realista, ainda que insólito - no sentido de fora do comum; ou o fenômeno fantástico se confirma, deslocando a obra para o campo do maravilhoso, do espaço da fantasia, de um mundo cujas regras se diferem das regras do mundo real; algumas poucas conseguirão, ainda, evitar a resolução dessa tensão, mantendo o fenômeno em suspensão, nunca explicado ou confirmado, obras que, para Todorov, explorariam um fantástico puro.

No entanto, já no final de sua obra, ao esbarrar com o século XX, Todorov precisa enfrentar um obstáculo chamado Kafka. Em A metamorfose, não somos expostos a um espaço realista, no qual, após uma série de indícios perturbadores, irrompe um fenômeno fantástico, que tira o mundo à sua volta do eixo, que infunde os personagens em horror e inquietação, como se espera nas obras desse tipo. Tampouco somos expostos a um mundo outro, com suas próprias regras de funcionamento e no qual seres e fenômenos sobrenaturais são da ordem cotidiana, como nos contos maravilhosos. A obra de Kafka apresenta um mundo nos moldes do espaço realista, mas, já de início, traz um evento insólito que, no entanto, não vem acompanhado do efeito de, pelo menos, inquietação e assombro, que se espera em uma obra típica do fantástico ${ }^{10}$.

10 Tal comentário é aplicável com mais facilidade ao A metamorfose, exemplo explorado por Todorov. Em outras obras do autor, como $O$ processo e $O$ castelo, esse fenômeno fantástico é menos explícito que no caso de Gregor, disperso pela própria construção do espaço ficcional, da reação dos personagens, da lógica de funcionamento do mundo. Pertencentes ao mesmo fantástico naturalizado, dariam, no entanto, mais trabalho para serem analisados, provavelmente o que explica a preferência de Todorov por trabalhar com A metamorfose. 
Todorov percebe que a lógica utilizada em Kafka é oposta à do fantástico tradicional: em vez de a obra partir do espaço realista para, num crescendo, alcançar o fenômeno sobrenatural, a obra parte de um efeito sobrenatural - a metamorfose de Gregor - para ir naturalizando esse efeito ao longo da obra, nos mostrando que, apesar da semelhança com o funcionamento do mundo real, o mundo ali representado é absurdo, funciona dentro de sua própria lógica de mundo (cf. TODOROV, 2007, p.179).

Se esse clima de absurdo, como vimos, já permeia Fargo de forma geral, esse fantástico naturalizado irrompe de forma mais explícita em dois fenômenos na obra. O primeiro deles diz respeito ao problema que antes apresentei sobre a invisibilidade de Gloria. A detetive, ao mesmo tempo em que evita a tecnologia, parece encontrar a mesma resposta por parte dos aparelhos eletrônicos. Desde o primeiro episódio, percebemos que Gloria é incapaz de ativar qualquer detector de presença: portas eletrônicas, luzes automáticas, pias e secadores automáticos não respondem a seus movimentos.

Conforme a história vai desenvolvendo melhor o personagem de Gloria, vamos percebendo que tal característica, ligada, claro, à sua tecnofobia, está também relacionada a sua sensação de não fazer parte do mundo, não ser notada. Em diálogo com sua ocasional parceira de investigação, a policial de tráfego Winnie Lopez, ela confessa, já exaurida pela constante frustração de sua investigação:

Sabe, antes de chegar aqui, estava pensando, Ennis, o meu padrasto escreveu uns livros sobre o espaço, ficção, acho. Li um deles. O planeta Wyh com o " $\mathrm{H}$ " no final. E era sobre um androide, acho que era isso, que... seu mestre morreu e ele vagou sozinho pelo universo por dois milhões de anos. [...] 
E ele só sabia dizer: "Posso ajudar". Mas não podia, ao menos, nunca conseguia. Mas ele continuava dizendo: "Posso ajudar". E continuava a falhar. $\mathrm{O}$ que, se tivesse que definir, é como me sinto na maioria dos dias. [...] E nos outros dias, para ser sincera, me sinto como... se fosse invisível. Invisível não... mas como se não fosse real. Faz sentido? [...] Tem o fato de que portas automáticas nunca se abrem para mim e os sensores, os... a torneira ou o dispersor de sabão nunca me sentem. E quando faço uma ligação ninguém me ouve. Então tenho uma teoria, em segredo, de que eu não existo. (HAWLEY, 2017, episódio 09, 41'54")

Se o episódio da investigação em Hollywood nada acrescenta ao enredo da descoberta dos crimes, colabora para o enredo típico da vertente metafísica na busca pela identidade. É descobrindo o passado de seu padrasto, lendo suas obras, que Gloria entende um pouco sobre a sua condição, para, posteriormente, se tornar capaz de sintetizar esse conhecimento na confissão que faz a Winnie. Essa jornada é tão importante para a narrativa quanto a jornada pela detecção, senão mais, já que, diferente da trama da investigação criminal, a trama pela investigação subjetiva tem um encerramento.

Winnie, diante da confissão, toma a única atitude possível para confortar uma pessoa derrotada pelo poder do discurso, uma pessoa que não se pode confortar através de palavras, que se mostraram ineficazes para dar conta da realidade: demonstra seu reconhecimento da existência de Gloria através de um abraço. Ao longo de toda a série, Gloria não recebe nenhum tipo de afeto muito claro: enfrenta um divórcio, seu pai e sua mãe estão mortos, a relação com o padrasto é distante e o filho, na pré-adolescência, 
não está em uma fase de dar ou receber carinho. A detetive, diante de tal situação, é definida por seu trabalho.

No entanto, sua única âncora de identidade começa a ruir quando perde seu posto de chefe de polícia. A chegada de Moe não representa apenas um problema na investigação, mas na sua própria concepção de si. Ao longo de toda a história, vemos a dificuldade de Gloria de se apresentar às pessoas porque é incapaz de sintetizar sua atual condição: ensaia dizer "chefe de polícia" e acaba tendo que adicionar um "ex" diante, dando uma impressão de que só é definida por suas relações com o passado, tal como sua visão de mundo e relação com a tecnologia.

Após receber esse abraço, contudo, Gloria passa a ter uma relação com o presente, um reconhecimento ligado, ao mesmo tempo, ao trabalho e à sua subjetividade. Nas palavras de Winnie: "Temos a ligação do nosso uniforme. Além disso, gosto de você" (HAWLEY, 2017, episódio 09, 44’38'). Em seguida, Gloria vai ao banheiro e os detectores passam a reconhecê-la, encerrando sua invisibilidade.

O fenômeno insólito é obviamente uma metáfora para sua condição. No entanto, a história, como no caso de Kafka, não pode ser simplesmente lida como uma alegoria. Não se trata de uma fábula, em que os personagens o enredo e a trama se articulam em prol da transmissão de uma mensagem subjacente à forma. Como defende Todorov, o relato deve ser lido, acima de tudo, como relato (cf. TODOROV, 2007, p.179) e é justamente pela incapacidade de ser facilmente resolvido como alegoria que seu efeito se torna tão complexo para o sistema conceitual todoroviano. 
A metáfora, ainda que metáfora, ganha existência plena e material no mundo narrativo, em uma lógica onírica, como Todorov propõe. A invisibilidade da detetive não se dá apenas no plano do conteúdo, não é algo que ela apenas sente, mas significa, de fato, um fenômeno insólito, ainda que naturalizado pela reação dos personagens.

Tal fenômeno se torna ainda mais visível na segunda manifestação sobrenatural da história. Nikki, que havia sido presa preventivamente pelo assassinato de Ray antes de Emmit se entregar, estava sendo transportada para uma prisão estadual. Temendo que a jovem acabasse delatando o pouco que sabia à polícia, Varga manda matá-la. Os capangas criam um acidente na estrada e invadem o ônibus de transporte de presos para assassinar a detenta, que consegue escapar com a ajuda de um ex-assassino de aluguel da primeira temporada da série ${ }^{11}$, Mr. Wrench.

Ambos fogem pelas florestas nevadas de Minnesota, perseguidos por Yuri, um assassino cossaco que trabalhava para Varga. A perseguição é sangrenta e termina com os três quase mortos chegando a uma súbita e quase deserta pista de boliche na beira da estrada. Lá, Nikki encontra um homem misterioso, que Ihe mostra um gato chamado Ray e Ihe fala sobre a reencarnação das almas. Ao longo da conversa, inicialmente absurda, vamos percebendo indícios de que aquele local se trata de uma fronteira entre a vida e a morte. Nikki crê que seu Ray havia voltado ao mundo como gato. O homem diz, então, que Nikki teria uma segunda chance, já que buscava vingança contra a vilania do mundo, e

11 A série, como disse, apresenta histórias isoladas em cada temporada. No entanto, personagens e eventos de uma temporada surgem em outras, dando a ideia desse espaço único que vai sendo montado de forma mais profunda e complexa a cada temporada. 
que permitiriam o mesmo a Wrench, que estava em caminho de redenção. Se a conversa ainda poderia ser vista apenas como um fenômeno estranho, com a partida de Nikki e posterior chegada de Yuri ao mesmo lugar, temos a confirmação do sobrenatural: Yuri conversa com o mesmo homem, que, dessa vez, condena seu interlocutor pelo assassinato de diversos judeus no passado, arrebatando, assim, sua vida.

Novamente, o que poderia ser apenas uma metáfora na obra, uma alucinação de quase morte, ganha materialidade: Nikki de fato passou pela pista de boliche, de tal forma que o próprio mensageiro do além lhe oferece a chave de um carro para voltar para a cidade.

A presença de tais fenômenos é ainda mais destacada pela ruptura com as convenções do gênero, retornando ao nosso ponto inicial. O gênero investigativo, desde sua raiz e até hoje, em suas vertentes mais convencionais, flerta com o insólito nos crimes, mas sempre o encerrando no campo do estranho. Não importa o quão sobrenatural o mistério do crime pareça, sua solução é alcançada através da investigação, que desvela seu funcionamento e desloca o crime para o campo do real, plenamente explicável.

O fator principal dessa escolha é simples: a narrativa investigativa tem como objeto central a representação ou reflexão sobre o crime e a justiça em seu contexto de produção. Inserir o sobrenatural na obra é distanciar o espaço narrado do mundo do leitor, logo, afastar a possibilidade de uma relação direta com o real.

No caso do romance de enigma tradicional, podemos ainda, adicionar a esse motivo outro relativo ao fair play esperado nessa 
vertente: um dos grandes prazeres levantados pelos teóricos do gênero em relação ao romance de enigma é a possibilidade que oferece ao leitor de, acompanhando a revelação das pistas, assumir ele mesmo a função de detetive e tentar, assim, resolver o caso. Tal possibilidade se vê profundamente prejudicada se, subitamente, as regras do mundo em que se passa a obra não forem pareadas às regras de funcionamento do mundo do leitor: se a obra aceita o sobrenatural como uma possibilidade, como o leitor, que desconhece as regras de funcionamento desse mundo sobrenatural, pode tecer com eficácia suas deduções?

Sendo a narrativa investigativa metafísica uma vertente comprometida com o questionamento das convenções do gênero, o sobrenatural, agora, ganha espaço ${ }^{12}$. O mistério para ser resolvido pelo leitor, nessa vertente, não é mais o do crime necessariamente, mas o da existência, da identidade, dos limites do conhecimento, da realidade. Nele, as questões sobre criminalidade e justiça dividem espaços com outras que dizem respeito à narrativa, à escrita e à tradição do gênero criminal.

\section{A LEI DOS LUGARES VAGOS}

A escolha do título desse artigo se dá pelo nome do primeiro episódio da terceira temporada de Fargo. É uma referência direta a um princípio do Bridge - jogo de cartas em que Nikki e Ray são competidores semiprofissionais - que determina a contagem das cartas e a possibilidade de previsão de uma carta específica na mão

12 Podemos, na literatura, ver um exemplo dessa quebra de convenção nas obras da detetive de Lucha Corpi, Gloria Damasco - que divide o primeiro nome com a detetive de Fargo. Gloria tem certo dom de clarividência que, ainda que não resolva os crimes, Ihe guia para um caminho talvez inalcançável para um detetive sem tal capacidade. 
de um jogador. Os lugares vagos, nesse sentido, são expectativas, são espaços que devem ser preenchidos e, se bem calculado, preenchidos por cartas específicas. É um cálculo de probabilidade. A analogia espelha o jogo entre espectador e obra ao longo da série. Fargo, ao explorar as convenções do gênero criminal, joga com as expectativas do leitor, com sua capacidade de previsão de comportamentos e enredos, subvertendo-os constantemente. Nikki é uma ex-detenta jovem, bonita e astuta que namora seu agente de condicional, Ray, fracassado, fora de forma, já com princípios de calvície e sem grande inteligência. Constrói-se a expectativa de que ela seja uma golpista, mas, no final, Nikki de fato o ama e permanece ao seu lado. Gloria é a detetive central da história, obstinada pela busca da verdade. Espera-se que ela triunfe, mas pouco sucesso é visto em sua jornada. A história diz-se baseada em fatos reais, e esperamos uma história realista apenas para encontrar uma narrativa que claramente expõe sua ficcionalidade e absurdo ao leitor.

Podemos, ainda - apesar de que apenas a tradução para português permita tal associação - pensar nos lugares vagos pela associação da obra ao indefinido. Varga se apresenta como eixo desse caráter difuso, de contornos turvos, poucas certezas que a história nos oferece. Isso se vê, desde o início, simbolizado pelo seu nome: ainda que provavelmente seja um nome falso e que nenhum mal haveria em revelá-los aos demais, Varga se apresenta como "V. M. Varga" e jamais revela o que as iniciais escondem. Da mesma forma, não sabemos nada de seu passado, em que mesmo o sotaque parece misturar diferentes influências linguísticas, corroborando a afirmação que faz de que é um "cidadão do mundo". Não sabemos 
exatamente se há uma organização criminal por trás dele ou se age sozinho, nem sabemos a extensão de sua influência, seus aliados ou situação financeira. Não tem casa, dorme em um caminhão adaptado como base de operações. Dessa forma, o personagem como um todo inspira esse temor difuso que, ao não deixar conhecer seus limites, o estende potencialmente a todos os espaços, fazendo com que os demais se sintam confinados nesse ambiente labiríntico típico da vertente metafísica da narrativa investigativa.

É, ainda, um lugar vago, o espaço que Fargo preenche enquanto obra de entretenimento popular dedicada à temática da investigação metafísica. Ainda que não seja pioneira, sem dúvida ajuda a preencher um espaço pouco habitado no nicho: um espaço de subversão de convenções, um espaço de desconforto ao público, que lhe nega o poder que geralmente a arte de massa oferece, de pautar a narrativa pelas suas expectativas. Com a chegada da quarta temporada em breve, veremos se a série será capaz de se manter nesse lugar vago ou, enfim, sucumbirá aos lugares-comuns da narrativa criminal contemporânea.

\section{REFERÊNCIAS}

AUDEN, W. H. (1980). "The Guilty Vicarage". In: WINKS, Robin W. Detective Fiction: a Collection of Critical Essays. Nova Jersey: Prentice-Hall.

BAUMAN, Zygmunt (1998). O mal-estar na pós-modernidade. Rio de Janeiro: Jorge Zahar Ed.

HAWLEY, Noah (2017). Fargo, 3a temporada, NETFLIX. In https://www.netflix. com/title/70285785 Acesso em 08.Abr.2020.

HAYCRAFT, Howard (1941). Murder for Pleasure. Nova lorque/Londres: D. Appleton-Century Company.

MERIVALE, Patricia; SWEENEY, Susan Elisabeth (1999). "The Game's Afoot: On the Trail of the Metaphysical Detective Story". In.: (Org.). Detecting 
Texts: the Metaphysical Detective Story from Poe to Postmodernism. Filadélfia: University of Pennsylvania Press.

SASSE, Pedro (2019). As narrativas criminais na literatura brasileira. (Tese Doutorado em Estudos de Literatura) 476f. Instituto de Letras, UFF, Niterói.

TODOROV, Tzvetan (2007). Introdução à literatura fantástica. Maria Clara Correa Castello (Trad.). São Paulo: Perspectiva.

WRONG, Edward Murray (1947). In: HAYCRAFT, Howard (Org.). The Art of the Mystery Story. Nova lorque: Grosset \& Dunlap. 